\title{
Substorm-related thermospheric density and wind disturbances derived from CHAMP observations
}

\author{
P. Ritter ${ }^{1}$, H. Lühr ${ }^{1}$, and E. Doornbos ${ }^{2}$ \\ ${ }^{1}$ Helmholtz-Zentrum Potsdam, Deutsches GeoForschungsZentrum - GFZ, Telegrafenberg, 14473 Potsdam, Germany \\ ${ }^{2}$ TU Delft, Department of Earth Observation and Space Systems (DEOS), Kluyverweg 1, 2629 HS Delft, The Netherlands
}

Received: 27 October 2009 - Revised: 28 April 2010 - Accepted: 19 May 2010 - Published: 1 June 2010

\begin{abstract}
The input of energy and momentum from the magnetosphere is most efficiently coupled into the high latitude ionosphere-thermosphere. The phenomenon we are focusing on here is the magnetospheric substorm. This paper presents substorm related observations of the thermosphere derived from the CHAMP satellite. With its sensitive accelerometer the satellite can measure the air density and zonal winds. Based on a large number of substorm events the average high and low latitude thermospheric response to substorm onsets was deduced. During magnetic substorms the thermospheric density is enhanced first at high latitudes. Then the disturbance travels at an average speed of $650 \mathrm{~m} / \mathrm{s}$ to lower latitudes, and 3-4h later the bulge reaches the equator on the night side. Under the influence of the Coriolis force the travelling atmospheric disturbance (TAD) is deflected westward. In accordance with present-day atmospheric models the disturbance zonal wind velocities during substorms are close to zero near the equator before midnight and attain moderate westward velocities after midnight. In general, the wind system is only weakly perturbed $\left(\Delta v_{y}<20 \mathrm{~m} / \mathrm{s}\right)$ by substorms.
\end{abstract}

Keywords. Ionosphere (Ionosphere-atmosphere interactions) - Magnetospheric physics (Storms and substorms) - Meteorology and atmospheric dynamics (Thermospheric dynamics)

\section{Introduction}

The energy input from the solar wind into the upper atmosphere is most efficiently coupled into the high-latitude ionosphere-thermosphere system. Several mechanisms channel part of the disturbances to low and mid-latitudes. Some

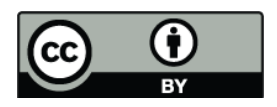

Correspondence to: P. Ritter

(pritter@gfz-potsdam.de) of these mechanisms cause a prompt response (e.g. the penetration electric field (Kikuchi et al., 1996)). Other processes require hours before the perturbation has reached the equator (e.g. travelling atmospheric disturbances). Here we focus on the thermospheric response to substorm onsets, i.e. density anomalies and thermospheric disturbance winds at high, mid and low latitudes as observed by CHAMP.

Substorms are regarded as an important part of the magnetospheric activity cycle and occur on average every $3 \mathrm{~h}$ during active periods. The loading by the solar wind is followed by an impulsive unloading of energy, previously stored in the magnetospheric tail, via currents flowing along the magnetic field lines into the ionosphere (Akasofu, 1964). Above the ionospheric footpoints of these field-aligned currents (FACs), a thermospheric mass density enhancement can be observed in the pre-midnight MLT sector (Liu et al., 2005).

Lühr et al. (2004) found that small-scale FACs in the cusp region can be associated with Joule heating and may thus be considered as one of the reasons for an air uplift and density enhancement in this region. In the meantime a number of dedicated studies have been devoted to the density anomaly related to the cusp (e.g. Schlegel et al., 2005; Demars and Schunk, 2007; Rentz and Lühr, 2008).

The issues we want to address here are the mass density anomalies caused by a substorm and their propagation to low latitudes. Large scale travelling atmospheric disturbances (TADs) are known to represent one mechanism to redistribute energy and momentum within the thermosphere in connection with magnetic activity (Hocke and Schlegel, 1996; Bruinsma and Forbes, 2007). Prölss (1982) investigated density perturbations at low latitudes during magnetically active periods. He found equatorial density humps developing only $4 \mathrm{~h}$ after substorm-related disturbances in the polar region and suggested TADs and large-scale wind circulation as driving mechanisms for the disturbance transport.

Many characteristics of TADs found in literature were derived from modelling efforts (e.g. Richmond and Matsushita,

Published by Copernicus Publications on behalf of the European Geosciences Union. 
1975; Fujiwara and Miyoshi, 2006, and references therein). From their global scale wave model they deduced several features: (1) TADs propagate towards the equator at a speed of $500-800 \mathrm{~m} / \mathrm{s}$ at altitudes above $300 \mathrm{~km}$; (2) the propagation path is bent westward by the Coriolis force; (3) the attenuation of the TAD amplitude on the dayside is larger than on the nightside.

For the variations of thermospheric winds caused by substorm injection Fujiwara et al. (1996) deduced from their model the formation of a vortical wind pattern in the meridional plane. It consists of upwelling air at high latitudes and of equatorward directed meridional winds at mid latitudes with velocities around $60 \mathrm{~m} / \mathrm{s}$. The transient pattern is associated with the formation of TADs.

We will compare our observations with these model results. Also the disturbance winds following a substorm are of interest. For both quantities we study the temporal and spatial variations which are obtained using CHAMP satellite accelerometer data. There are very few superposed epoch analyses performed on these parameters in literature. Compared to studies presented earlier by e.g. Burns and Killeen (1992) or Emmert et al. (2002) which are dealing with the effect of magnetic activity on thermospheric winds in general, our studies are based on higher time resolution and on a large number of discretely identified substorm events.

CHAMP accelerometer measurements provide the opportunity for detailed statistical studies of substorm-related thermospheric effects at all latitudes and Magnetic Local Times (MLT). Significant results for several aspects were obtained by using the extensive substorm onset catalogue of Frey and Mende (2006) with its more than 4000 entries of identified events. The time span covered by this catalogue overlaps well with the high-resolution accelerometer measurements of CHAMP (2001 to present). Thus it can be used broadly to perform statistics aiming to disclose substorm-related features in satellite data.

In the following Sect. 2 we introduce the substorm catalogue and the CHAMP data used in this study. In Sect. 3 we present the observations of a single substorm event. We show mass density and zonal wind velocity readings along consecutive orbits at high and low latitudes. Section 4 describes the statistical studies of these quantities for magnetically active and quiet periods. In Sect. 5 we discuss the observational results and compare them to model predictions found in literature. Section 6 provides a summary of this study.

\section{Datasets}

\subsection{IMAGE FUV - substorm catalogue}

Substorm onset times are identified from the images of the far ultra-violet (FUV) instrument on board the IMAGE spacecraft, using the Wideband Imaging Camera (WIC) and the Spectrographic Imager Channel (SI-13). For the statistical study we used the catalogue of substorm onset times by Frey and Mende (2006) listing approximately 4200 events during the years 2000-2005. For the substorm recognition three conditions were used: i) a clear local brightening of the aurora; ii) its expansion to the poleward boundary of the auroral oval and a minimum azimuthal spread of $20 \mathrm{~min}$ in local time; iii) a gap of $30 \mathrm{~min}$ between events. The IMAGE spacecraft observed the auroras of the Northern Hemisphere in 2000-2003 and then moved to the Southern Hemisphere. In the Northern Hemisphere, 2760 substorm onsets were identified, while in the Southern Hemisphere 1430 events were detected.

The mean substorm onset location is the same in both hemispheres when averaged over all seasons and years: it occurs at $22.9 \mathrm{~h}$ MLT (magnetic local time) and $66.4^{\circ}$ of magnetic latitude, regardless of the different general magnetic activities of the two subsets (Wang et al., 2005, 2007). Most substorms occur at $\mathrm{Kp}<4$ (Ritter and Lühr, 2008).

\subsection{CHAMP orbits and data}

The thermospheric mass density and zonal wind data used in this study are derived from the STAR (Space Three-axis Accelerometer for Research Missions) acceleration measurements on board the CHAMP satellite. CHAMP (Reigber et al., 2002) was launched on 15 July 2000 into a circular, near-polar $\left(87.3^{\circ}\right.$ inclination) orbit. From its initial altitude at $456 \mathrm{~km}$ the orbit decayed to about $350 \mathrm{~km}$ during the first 5 years. The orbital plane of the low Earth orbiting (LEO) spacecraft precesses by $1 \mathrm{~h}$ of local time (LT) in 11 days, thus after 131 days all local times are covered.

The accelerometer dataset employed for this study was recently newly calibrated, and subsequently processed into density and wind datasets (Doornbos et al., 2010). The calibration of the in-track accelerometer axis was performed by solving for daily accelerometer biases using independent GPS satellite-to-satellite tracking data (VanHelleputte et al., 2009). This procedure was performed for data from 5 May 2001 onwards. For the cross-track axis calibration, an aerodynamic model of the satellite was applied to get more accurate results. In addition, extreme outliers, spacecraft attitude manoeuvre effects, and accelerations due to solar radiation pressure were removed. The data were averaged over a time interval of $10 \mathrm{~s}$ which results in a spatial resolution of $76 \mathrm{~km}$.

The thermospheric mass density and zonal wind are derived from the in-track and cross-track axes acceleration measurements by means of a newly developed processing approach. In an iterative procedure, the modelled aerodynamic force is varied until it coincides with the observed acceleration. The magnitude of the acceleration is fit by adjusting the air density entering the prediction model, while the direction of the acceleration is fit by adjusting the crosswind speed. Special emphasis was put on the proper characterization of the aerodynamic interaction of the thermospheric particles with CHAMP's outer surfaces. For full details of the 
processing algorithm we refer the reader to Doornbos et al. (2010).

With these refinements, the accuracy of the density and wind measurements were improved over previous studies. The resolution of the density measurements is estimated at around $5 \times 10^{-14} \mathrm{~kg} / \mathrm{m}^{3}$ and the wind speed resolution is about $\pm 10 \mathrm{~m} / \mathrm{s}$. The studies presented subsequently rely primarily on the comparison between the conditions before and after a substorm. For that reason the absolute accuracy of the density and wind measurements is of minor concern for the conclusions drawn.

All density data were normalized to $400 \mathrm{~km}$ altitude to exclude variations due to orbital height $(h)$ changes during the time span used for the statistics. The normalization $\rho(400 \mathrm{~km})=\rho(h) \cdot\left(\rho_{\mathrm{M}}(400 \mathrm{~km}) / \rho_{M}(h)\right)$ was done using model densities, $\rho_{\mathrm{M}}$, determined from the NRLMSISE00 atmospheric model (Picone et al., 2002).

\subsection{Magnetic coordinates}

All CHAMP satellite readings used for the superposed epoch analyses presented in the following sections are treated in magnetic quasi-dipole (QD) coordinates as defined by Richmond (1995). The substorm onset locations identified by IMAGE FUV are given in apex latitudes and magnetic local times according to the same system as proposed by Richmond (1995).

\section{Example of a substorm event}

Before presenting the statistical study we introduce as an example the thermospheric mass density and wind observations of a single substorm event at high and low latitudes by the CHAMP satellite. IMAGE FUV auroral observations identified the onset time of this example substorm at $T_{0}=18: 34: 29$ UT on 14 November 2003. Its onset location in the Mlat/MLT frame is at $67.89^{\circ}$ Mlat, 00:53 MLT. Figure 1 presents the zonal wind velocity (top panel) and mass density (second panel) of 4 consecutive CHAMP orbits, starting with the orbit preceding the substorm onset $T_{0}$ (marked by an asterisk). The panels below show the geomagnetic latitude and magnetic local time of the satellite trajectory. The spacecraft crosses the equator in northward direction shortly before local midnight and in southward direction close to noon.

The strongest variations of the zonal wind and mass density can be observed at polar latitudes. Outside the auroral regions we find some common features repeatedly in each orbit. On the dayside the density, rho, is higher by a factor of approximately 1.5 compared to the nightside.

The winds at mid and low latitudes are directed, as expected (Drob et al., 2008), predominantly eastward on the nightside and westward on the dayside. Generally, the wind speeds reach a local maximum near the equator. However, the predominant features are the negative peaks on the day- side, surpassing $-400 \mathrm{~m} / \mathrm{s}$ at high latitudes. These strong westward winds blowing from the day to the night side across the dawn sector in the auroral region have been reported earlier (e.g., Lühr et al., 2007; Förster et al., 2008).

In this study we are interested in substorm related phenomena. For a better visualization of the temporal and spatial effects we use a common colour coding for the successive orbits throughout this paper. As can be seen in Fig. 1, the nightside pass before the substorm onset $T_{0}$ is marked black, the first one after $T_{0}$ is red, the second one blue, and the third one green. The related parts of the wind and density observations are highlighted in Fig. 1 using the same colour scheme. No strong thermospheric effects can be discerned during the passes following the substorm onset. However, some subtleties still emerge. The eastward wind at the equator gets weaker from the black pass through the red one to the blue one, but it recovers during the green one. When looking at the densities the only significant feature seems to be the peak near the equator during the green pass.

From this one event we may conclude that a substorm initiates a westward disturbance wind on the nightside at low and mid latitudes, as well as a density enhancement travelling equatorward and reaching it after $3-4 \mathrm{~h}$. In order to test the significance of these findings we performed a statistical analysis, making use of all close encounters of the CHAMP satellite with substorms reported in the catalogue.

\section{Statistical analysis}

For our statistics we used the large number of substorm events $(>4000)$ available in the catalogue of Frey and Mende (2006) and subjected the related data to superposed epoch analysis. Usually this method is used to stack time series relative to a key-time defined by the event to be analysed. For satellite data, however, it can be used to estimate eventrelated mean data profiles along certain latitudinal sections. In our study superposed epoch analysis was used as a tool to obtain mean mass density and wind velocity profiles at the northern polar region and at mid/low latitudes in the nighttime MLT sector after substorm onsets. As we wanted to obtain a comprehensive picture of the temporal and spatial effects on thermospheric dynamics, we selected the events according to several criteria. One of them is the prevailing magnetic activity: substorms occurring during active $(\mathrm{Kp}>4)$ and quiet $(\mathrm{Kp} \leq 2)$ periods were considered separately. Furthermore, we sorted the observations into three consecutive MLT bins extending from $2 \mathrm{~h}$ MLT before the onset location to $4 \mathrm{~h}$ MLT past it.

Due to the fact that the satellite crosses various MLT sectors in the polar regions on its pass, the selection of suitable orbit sections was performed separately for polar and mid/low latitude profiles. At high latitudes, nighttime data of intervals $\left[40 \ldots 80^{\circ}\right]$ Mlat were stacked. For the analysis at lower latitudes nighttime sections of $\pm 50^{\circ}$ centred at the 

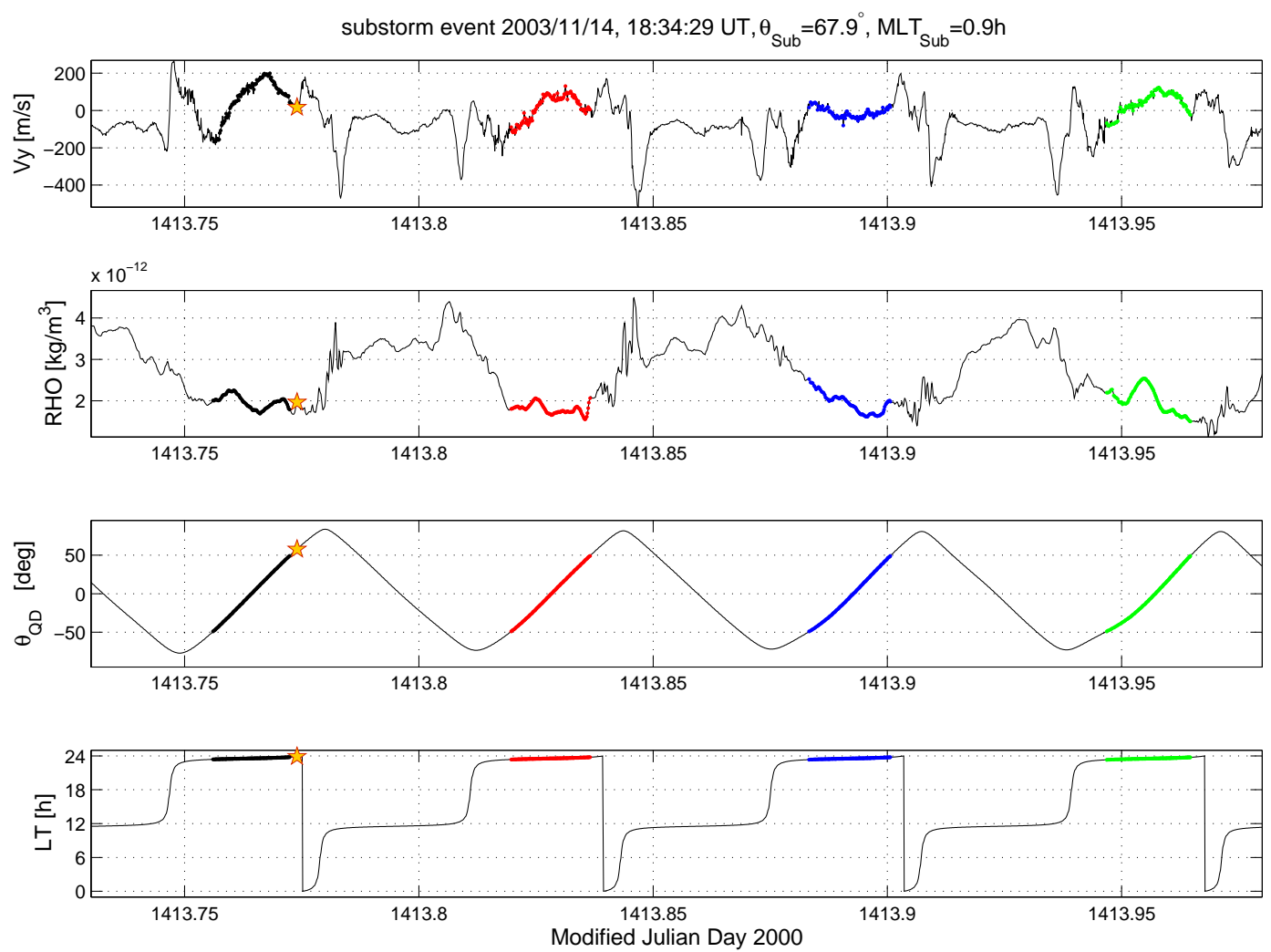

Fig. 1. Example of thermospheric density and wind variations along subsequent orbits before and after a substorm onset. The substorm onset $T_{0}$ takes place on 14 November 2003 at 18:34:29 UT. It is marked by an asterisk on the curves. Top frame: zonal wind $v_{y}$; second frame: mass density; third frame: Quasi-Dipole latitude; bottom frame: MLT. The orbit sections used for the superposed analysis (equatorial profiles) are marked with black, red, blue, and green colors for the passes before, first, second, third pass after $T_{0}$, respectively.

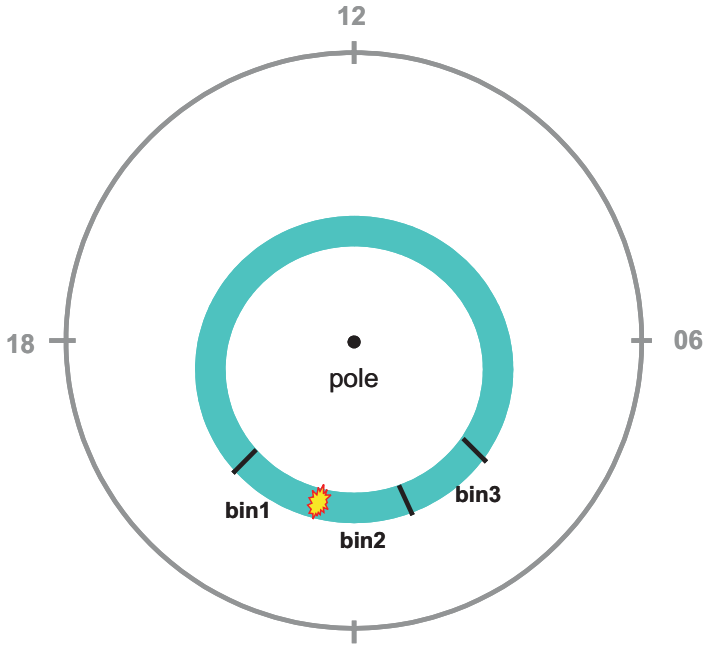

00

Fig. 2. Scheme of LT binning. Observations are sorted into three local time sectors wrt. the individual onset location. bin 1: $0-2 \mathrm{~h}$ MLT before substorm onset; bin 2: 0-2 h MLT past onset; bin 3: 2-4 h MLT past onset. geomagnetic equator were used. This separation ensures also a minimum blending of temporal and spatial information.

Generally, the nighttime data were selected from orbits within the local time sector from $21 \mathrm{~h}$ to $3 \mathrm{~h}$ MLT i.e. they cross the average substorm onset latitude within a time interval of $-2 \mathrm{~h}$ and $+4 \mathrm{~h}$ with respect to mean $T_{0}$. Furthermore, the actual MLT difference between the satellite pass and the individual onset location was used to group the data into three further subsets: $[-2 \ldots 0 \mathrm{~h}],[0 \ldots 2 \mathrm{~h}]$, and $[2 \ldots 4 \mathrm{~h}]$ MLT sectors relative to the onset. For this sorting the MLT of the satellite at the magnetic latitude of the average onset location was used. As the substorm location depends on the magnetic activity (Wang et al., 2005) we used an equation given therein to determine the average onset latitude for the low and high activity datasets separately: $|\theta|_{0}=73^{\circ}-5.2 \sqrt{E_{\mathrm{m}}}$. As a proxy for the geomagnetic activity the merging electric field was assumed $E_{\mathrm{m}}=4 \mathrm{mV} / \mathrm{m}$ for $\mathrm{Kp}>4$ conditions, and $E_{\mathrm{m}}=0.8 \mathrm{mV} / \mathrm{m}$ for the low activity dataset with $\mathrm{Kp} \leq 2$. In the following, the results of the three MLT subsets are referred to as bins 1, 2, 3, respectively, as illustrated in Fig. 2.

Orbital arcs before and after a substorm onset were compared. To obtain well-timed "after" arcs, substorm onsets had to occur before the satellite sampled the latitudinal profile on 

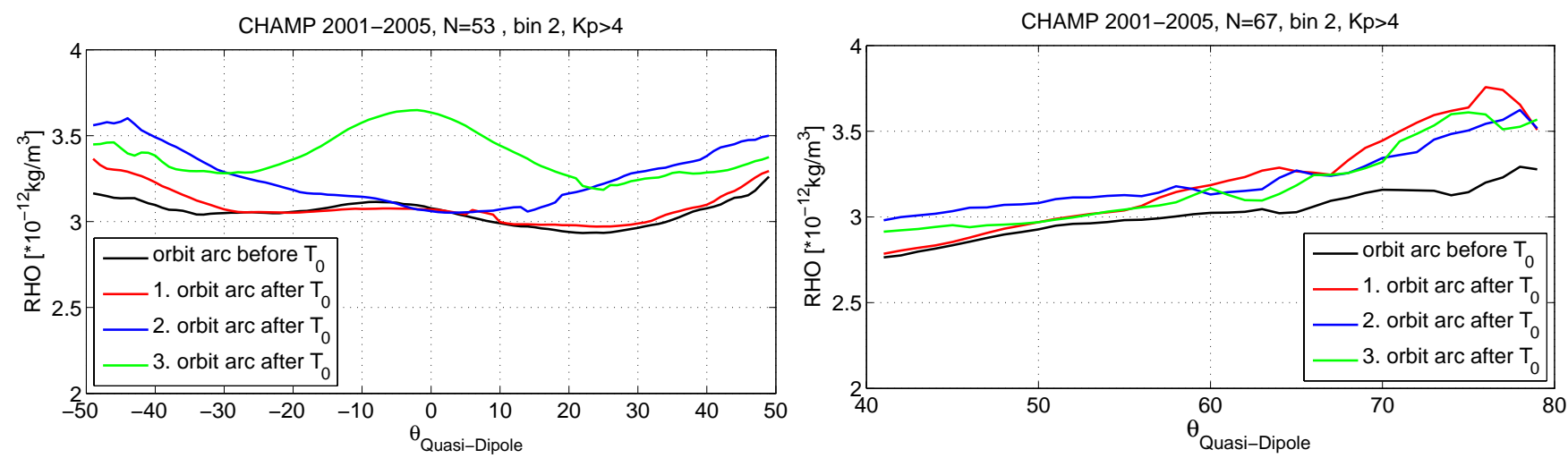

Fig. 3. Mean thermospheric density at low (left frame) and high (right frame) latitudes for $\mathrm{Kp}>4$ of data subsets in bin 2 . Black line: orbit arc before substorm onset $T_{0}$; red line: $0.25-1.25 \mathrm{~h}$ after substorm onset $T_{0}$; blue line: $1.75-2.75 \mathrm{~h}$ after $T_{0}$; green line: $3.25-4.25 \mathrm{~h}$ after $T_{0}$. Calculated mean MLT: $24 \mathrm{~h}$. The mean uncertainty of the density curves is $\pm 0.2 \times 10^{-12} \mathrm{~kg} / \mathrm{m}^{3}$.
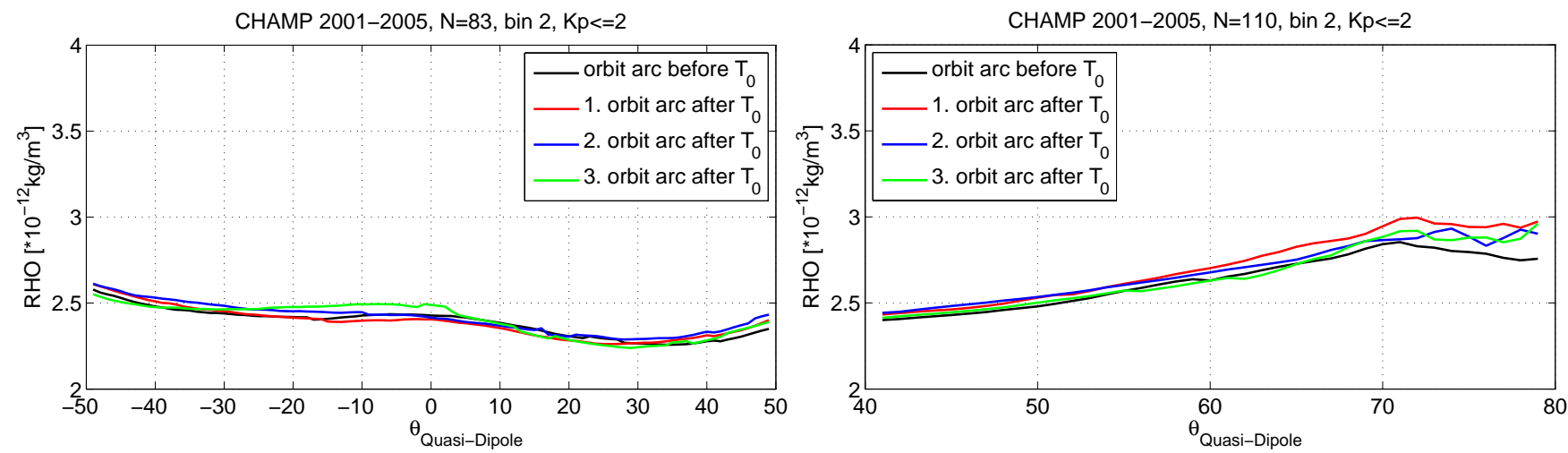

Fig. 4. same as Fig. 3, but for low magnetic activity (Kp $\leq 2)$. Calculated mean MLT: $24 \mathrm{~h}$.

the night side. The satellite needs approximately $10 \mathrm{~min}$ to cross the high latitude profile, and about 25 min to cross the mid/low latitude profile. The previous night-side pass, occurring $1.5 \mathrm{~h}$ earlier, was declared "before" pass. According to this definition CHAMP sampled the magnetic field variations at the nightside equator at its first pass after the break-up with a delay ranging between 12 and $77 \mathrm{~min}$ after $T_{0}$.

Following this procedure, more than 1000 substorm events from the substorm catalogue could be used for the CHAMP superposed epoch analysis (1120 events on the mid latitude profile, 1290 on the polar profile). Since we subdivided the data according to several criteria, there are about 50 events in every local time bin for active periods and around 100 events for quiet periods. We regard these numbers sufficient for retrieving statistically significant results. The difference between the "before" and "after" passes reflects the average latitudinal wind velocity or density variations associated with a substorm onset.

\subsection{Thermospheric mass density}

Before analysing the substorm-related effects a look at the average prevailing condition during the considered events helps to judge and interpret the significance of the substorm effects. Figure 3 shows the average density profiles of the high activity events for the subset around midnight (bin 2). At mid latitudes (left frame) the pre-substorm pass exhibits a rather flat latitude profile with a shallow maximum near the equator. Such a pre-midnight density anomaly has been reported earlier (e.g. Liu et al., 2005). The density increases towards high northern latitudes, as is confirmed by the frame on the right side. Passes after the substorm onset show higher densities. The affected latitudes seem to depend on the latency after the substorm onset. During the third pass a quite prominent density bulge at the equator emerges. An indication of that process is evident already in the example presented in Fig. 1. In the subsequent Fig. 4 we present the average density curves for substorms occurring during quiet periods of $\mathrm{Kp} \leq 2$ in a similar way.

The difference curves of thermospheric mass density for the first three satellite passes after substorm onset are shown 

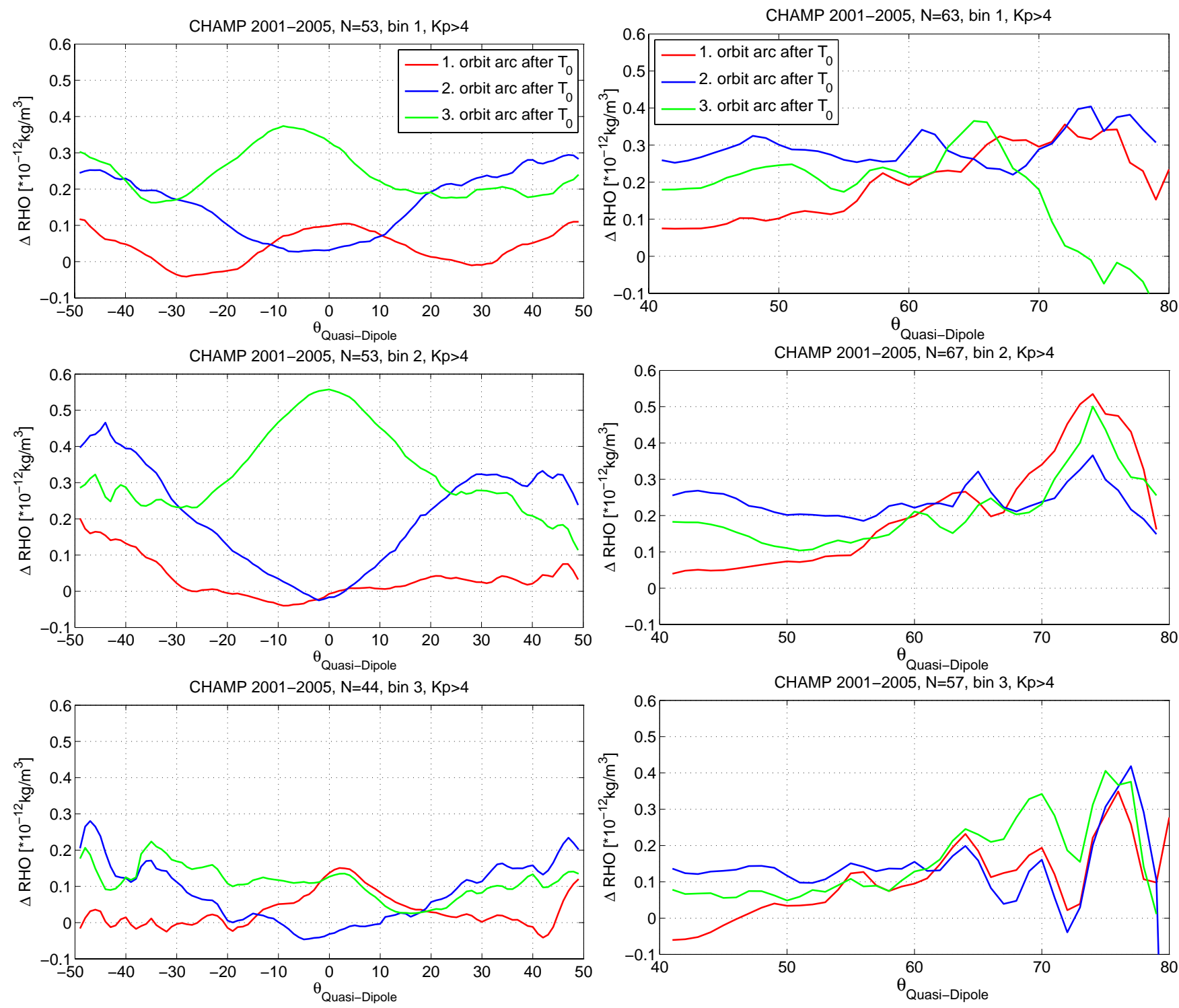

Fig. 5. Differences of thermospheric density, data before a substorm onset are subtracted from data after $T_{0}$, at low (left column) and high (right column) latitudes for $\mathrm{Kp}>4$. Frames from top to bottom contain subsets of bins 1,2,3 with calculated mean MLT $22.5 \mathrm{~h}, 24.0 \mathrm{~h}, 1.0 \mathrm{~h}$, respectively. Red line: $0.25-1.25 \mathrm{~h}$ after substorm onset $T_{0}$; blue line: $1.75-2.75 \mathrm{~h}$ after $T_{0}$; green line: $3.25-4.25 \mathrm{~h}$ after $T_{0}$. The mean uncertainty of the density curves is $\pm 0.1 \times 10^{-12} \mathrm{~kg} / \mathrm{m}^{3}$.

in Fig. 5, for the mid/low latitude (left column) and the polar profiles (right column). From top to bottom the curves represent the data subsets of the MLT bins 1,2,3 (see Fig. 2). The three curves in each graph show the average of the differences between the first, second, and third passes after the substorm onset to the curves before $T_{0}$. The color codes follow the scheme given in Fig. 1. Subsequent passes are separated by $93 \mathrm{~min}$, respectively. The datasets for the polar and equatorial profiles are not based on exactly the same events because the MLT requirements for nighttime selection were applied to the entire length of each profile. Nevertheless, polar and equatorial mean variations agree rather well in the overlapping parts.
For the discussion of the mass density modification after a substorm we start with the observations in the northern polar region (right column of Fig. 5). The top frame contains the observations from the local time sector centred at $1 \mathrm{~h}$ west of the substorm onset location. On the first pass after the onset (red curve) we observe a broad enhancement reaching from $55^{\circ}$ to $80^{\circ}$ Mlat. On the second pass the density is elevated over the whole latitudinal range. The green curve (3rd pass) exhibits a peak near $65^{\circ}$ Mlat and drops off considerably towards high latitudes. This issue will be discussed in Sect. 5.1.

In bin 2, which is centred around local midnight, we find the largest mass density enhancements reaching about $20 \%$ 

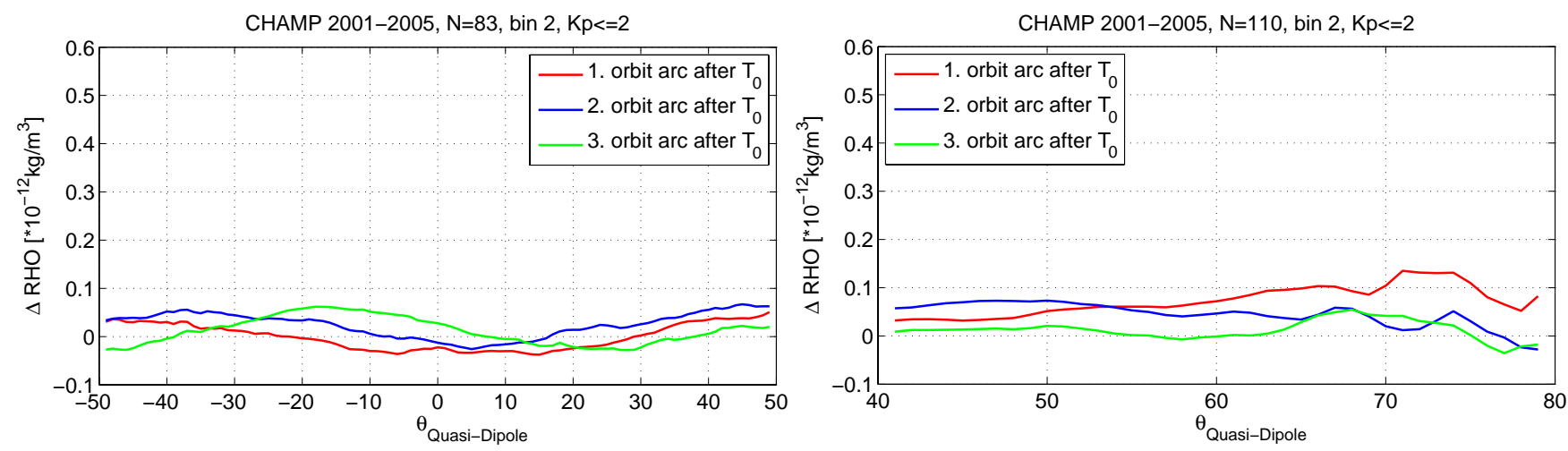

Fig. 6. same as Fig. 5, but for low magnetic activity (Kp $\leq 2)$. Calculated mean MLT: $24 \mathrm{~h}$.
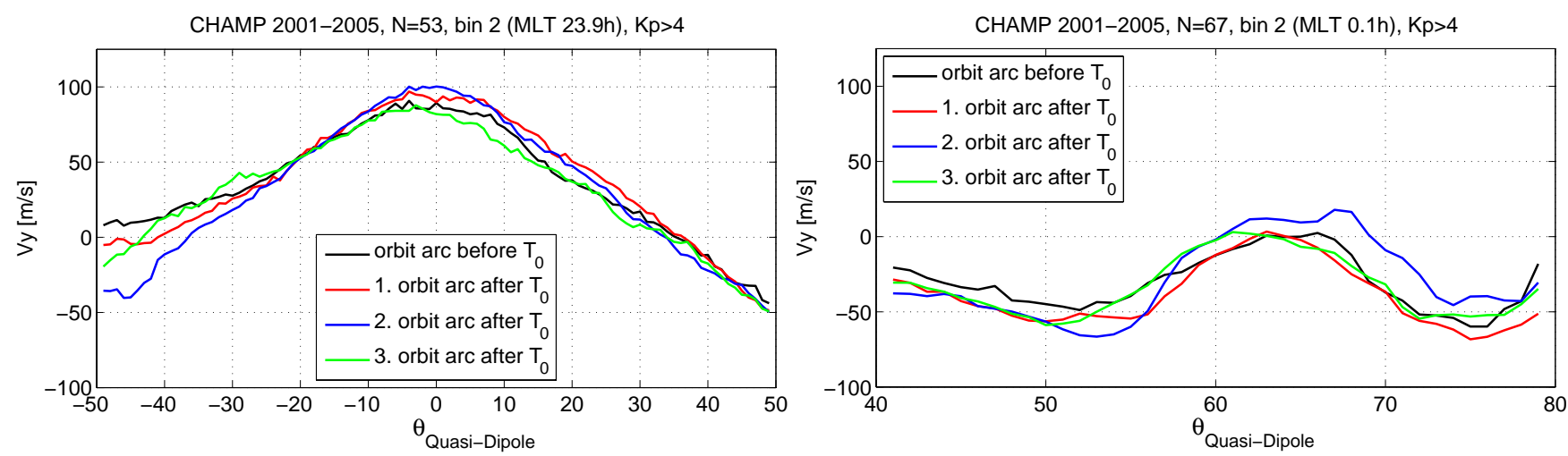

Fig. 7. Mean thermospheric wind velocity at low (left frame) and high (right frame) latitudes for Kp $>4$ of data subsets in bin 2 . Black line: orbit arc before substorm onset $T_{0}$; red line: $0.25-1.25 \mathrm{~h}$ after substorm onset $T_{0}$; blue line: $1.75-2.75 \mathrm{~h}$ after $T_{0}$; green line: $3.25-4.25 \mathrm{~h}$ after $T_{0}$. Calculated mean MLT: $24 \mathrm{~h}$. The mean uncertainty of the zonal wind curves is $\pm 15 \mathrm{~m} / \mathrm{s}$.

of the ambient value. All curves peak at $74^{\circ}$ Mlat. This indicates the latitude where the main heating process may be assumed to take place. As expected, the largest and most confined density maximum is recorded on the first pass after onset. The blue, second curve shows again a broad enhancement over all latitudes. The late, green curve reveals a surprisingly peaked shape for which we will offer an explanation in Sect. 5.

The substorm effect in the local time sector past midnight (bin 3) is much reduced. In general we observe only narrow peaks near $75^{\circ}$ Mlat.

The substorm related mass density observations at mid and low latitudes (left column of Fig. 5) reveal a number of interesting features. Most prominent is the density bulge at the equator detected on the third pass after onset. This feature is strongest around midnight but present also in the local time sector west of the onset location. Interestingly, we hardly find any density modification at mid latitudes in the pastmidnight sector (bottom frames). The sequential change of the curves in the two upper frames suggests an equatorward propagation of the high-density bulge from both auroral regions. At the time of the red curve the front has reached about $40^{\circ}$ Mlat, on the next pass (blue) $20^{\circ}$, and finally both bulges pile up at the equator by the time of pass 3 , about $4 \mathrm{~h}$ after the substorm onset. When placing the heating region at $74^{\circ}$ we obtain an average propagation velocity of $650 \mathrm{~m} / \mathrm{s}$ towards the equator (travelling path: $2 \pi r_{\text {sat }} \cdot 74^{\circ} / 360=8745 \mathrm{~km}$, with $r_{\text {sat }}=6766.5 \mathrm{~km}$ being the mean satellite altitude on the path from $74^{\circ}$ Mlat to the magnetic equator; travelling time: $3.75 \mathrm{~h}$ on average). The timing uncertainty of $\pm 0.5 \mathrm{~h}$ results in an error of $15 \%$.

The minor equatorial density bulge of the red curve in the top frame is slightly unexpected. We will return to this feature in Sect. 5.

A comparison of the thermospheric density variations before and after substorms during magnetically quite periods $(\mathrm{Kp} \leq 2)$ is shown in Fig. 6. Obviously the amplitudes of these variations are much smaller than those of the high activity data in Fig. 5. The pattern of density enhancement moving from the North Pole to the equator with increasing time lag to the substorm onset, however, can also be observed. The low activity curves show smoother variations. This is probably partly due to the larger sample number of substorms for conditions with $\mathrm{Kp} \leq 2$. The subsets presented in Fig. 6 contain 

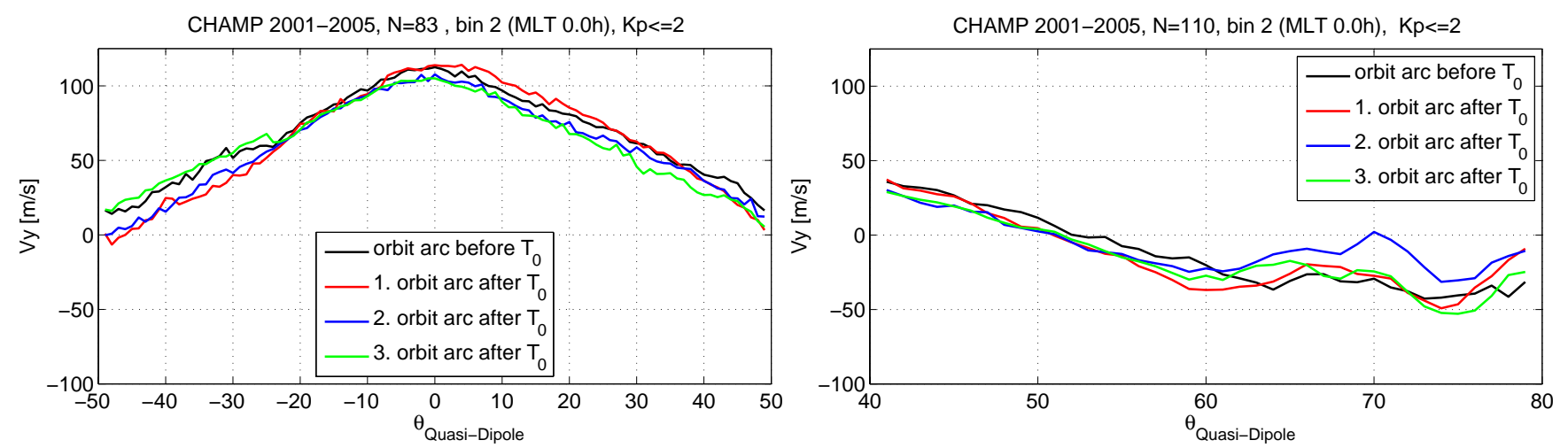

Fig. 8. same as Fig. 7, but for low magnetic activity (Kp $\leq 2)$. Calculated mean MLT: $24 \mathrm{~h}$.

almost twice as many events as those for higher activity. Due to the marginal effect we will not discuss these low activity results further.

\subsection{Thermospheric zonal wind disturbance}

Similar to the density results we start with presenting the average background wind during the selected events. Positive velocities represent eastward winds. As shown for active periods in Fig. 7 (left frame) we observe prevailing eastward winds at low latitudes on the night side that peak at the equator. Poleward of $40^{\circ}$ Mlat they switch to westward directions. All four curves are close to each other indicating that substorms do not have a strong influence on the zonal wind at mid latitudes. At high northern latitudes we find westward wind velocities peaking around $53^{\circ}$ and $74^{\circ}$ Mlat. At $63^{\circ}$ Mlat the zonal wind dies down.

For comparison, the average zonal wind velocities during the low activity substorm events are shown in Fig. 8.

Figure 9 shows the difference curves of thermospheric zonal wind velocity of the first three satellite passes after substorm onset with respect to the pre-event condition at mid and low latitudes (left column) and the polar profiles (right column). As for the density curves in Fig. 5, the frames from top to bottom present the data subsets of the 3 MLT bins, and each graph contains the difference curves of the first, second, and third passes after the substorm onset. The data were sampled after substorms occurring during magnetically active periods $(\mathrm{Kp}>4)$.

As stated earlier the substorms-induced wind modifications are rather weak. At low latitudes we observe almost no deviation in all three local time sectors. At mid latitudes most of the significant disturbance winds are found in the local time sector west of the substorm onset location. The westward component increases from approximately $20 \mathrm{~m} / \mathrm{s}$ on the first pass after onset to around $40 \mathrm{~m} / \mathrm{s}$ on the third pass. Within the other time sectors no clear wind signature could be deduced.
At high northern latitudes the disturbance winds have a slightly different character. While equatorward of $55^{\circ}$ they are weakly westward in all three local time sectors, the delta wind at auroral latitudes tends to be directed eastward in MLT bin 1, varies around zero in bin 2, and exhibits a clear westward component in bin 3 . When relating these observations to the background winds shown in Fig. 7 (right frame) we may conclude that the sub-auroral westward winds are enhanced by the substorm. Conversely, the high-latitude westward winds are weakened in the late evening and significantly enhanced in the post-midnight sector by substorm activity.

At lower magnetic activities, shown for substorm events with $\mathrm{Kp} \leq 2$ in Fig. 10, the disturbance wind patterns have only small amplitudes. As these variations are of the order of the uncertainty range we do not subject them to further interpretation.

\section{Discussion and conclusions}

The aim of this study is to identify the average thermospheric mass density and zonal wind disturbances caused by a substorm over the entire range of latitudes. We used the multitude of substorm events catalogued by Frey and Mende (2006) covering the period from the middle of 2000 to the end of 2005.

The input of energy and momentum from the magnetosphere into the atmosphere occurs during geomagnetic storms and substorms primarily at high latitudes. In this region, field aligned currents (FACs) connect the auroral ionosphere with the magnetopause, the tail and the ring current systems.

During active periods there is a continuous energy influx from directly driven processes and impulsive energy injections from loading and unloading processes in the magnetotail take place. Magnetospheric currents, directly driven by the solar wind, are connected predominantly to the dayside auroral region. Conversely, the transient substorm-related 

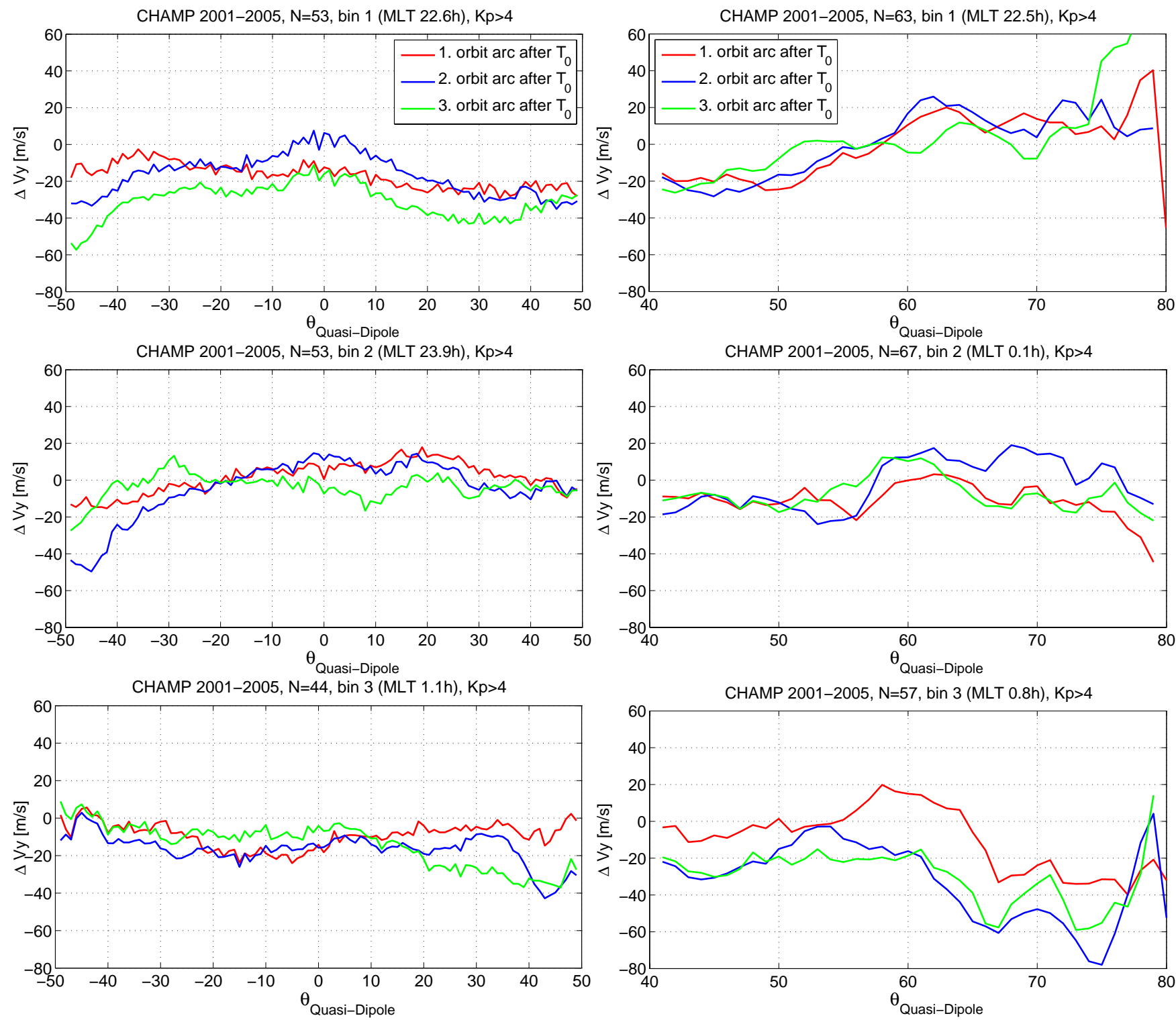

Fig. 9. Differences of zonal wind velocity, data before a substorm onset are subtracted from data after $T_{0}$, at low (left column) and high (right column) latitudes for Kp $>4$. Frames from top to bottom contain subsets of bins 1,2,3 with calculated mean MLT $22.5 \mathrm{~h}, 24.0 \mathrm{~h}, 1.0 \mathrm{~h}$, respectively. Red line: $0.25-1.25 \mathrm{~h}$ after substorm onset $T_{0}$; blue line: $1.75-2.75 \mathrm{~h}$ after $T_{0}$; green line: $3.25-4.25 \mathrm{~h}$ after $T_{0}$. The mean uncertainty of the zonal wind curves is $\pm 7 \mathrm{~m} / \mathrm{s}$.

currents are routed through the nightside auroral ionosphere (Caan et al., 1975; Ritter and Lühr, 2008).

As a consequence of magnetic activity the thermospheric mass density is enhanced in the cusp region and near the midnight sector (e.g., Liu et al., 2005; Kwak et al., 2009), i.e. in regions of the main Region-1 and Region-2 FACs footprints.

The cusp-related mass density anomaly has been studied in detail by Rentz and Lühr (2008). Due to its directly driven character the thermospheric effect in this region can be correlated straight-forward with the solar wind input. In the case of substorms we are dealing with discrete injection. There- fore, techniques other than plain correlations between activity indices and thermospheric effects are required. In the study presented here, superposed epoch analysis is used with satellite data on a large number of substorm events for the determination of the temporal and spatial evolution of thermospheric disturbances caused by a substorm.

\subsection{Thermospheric mass density effects}

For our analysis we divided the nightside data related to substorms into two subsets, one containing all events during periods of high magnetic activity $(\mathrm{Kp}>4)$ and one that 

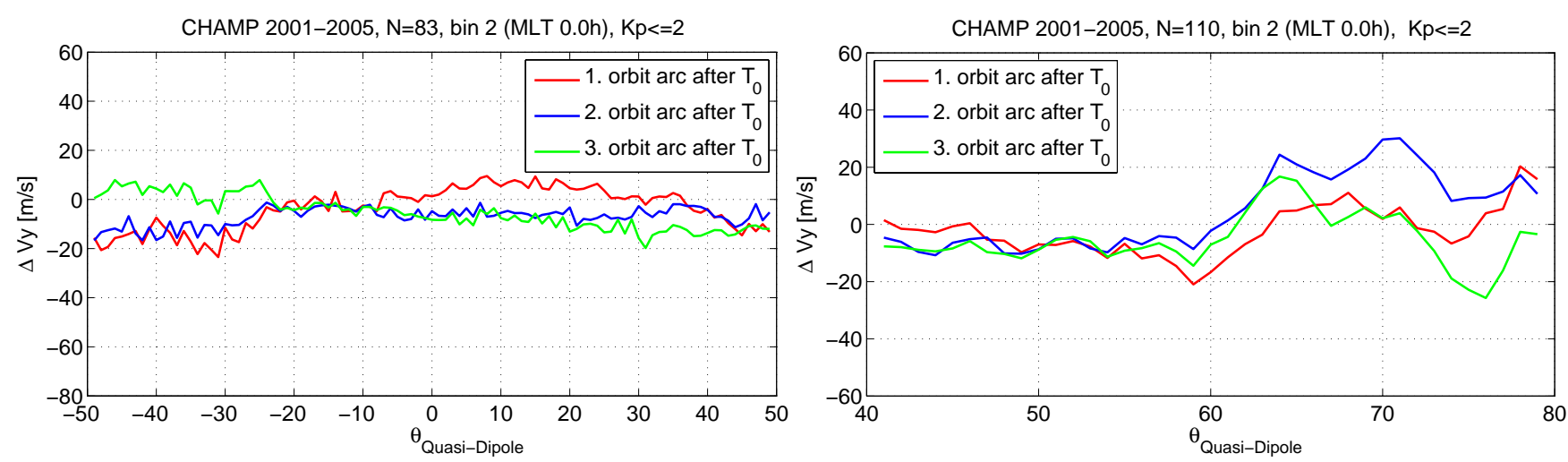

Fig. 10. same as Fig. 9, but for low magnetic activity $(\mathrm{Kp} \leq 2)$. Calculated mean MLT: $24 \mathrm{~h}$.

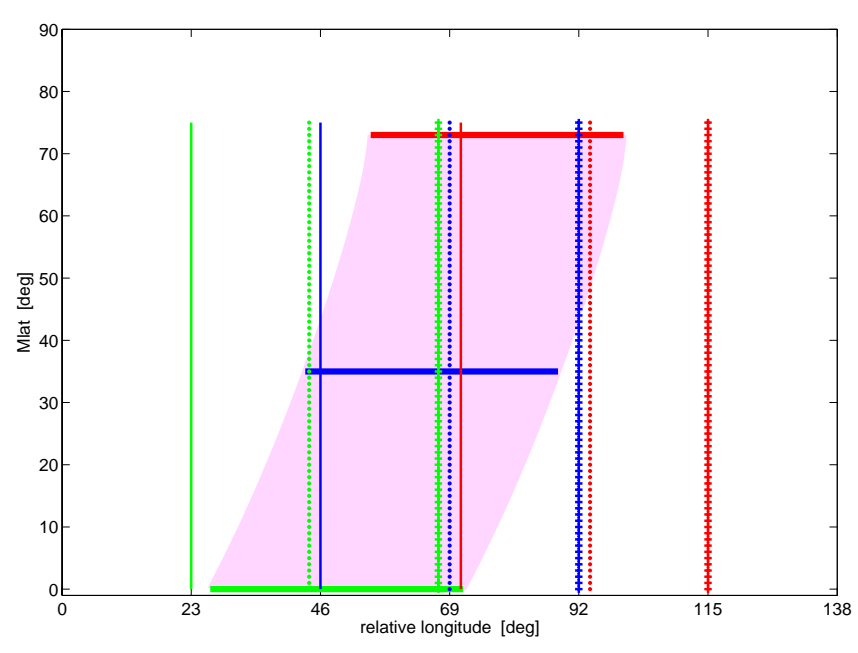

Fig. 11. Sketch of the longitudinal coverage by the various data subsets, selected by orbit sequence and bins. Red: $0.25-1.25 \mathrm{~h}$ after substorm onset $T_{0}$; blue: $1.75-2.75 \mathrm{~h}$ after $T_{0}$; green: $3.25-4.25 \mathrm{~h}$ after $T_{0}$. Solid lines: bin 1 ; dots: bin 2; crossed lines: bin 3 . The pink background marks the path of the TAD front deflected by Coriolis force.

contained only low activity substorms $(\mathrm{Kp} \leq 2)$. The finite number of suitable substorms prevented a further breakdown of the subsets. We also tested a classification by the auroral activity index $\mathrm{AE}$, with $\mathrm{AE}>500 \mathrm{nT}$ for active periods and $\mathrm{AE}<200 \mathrm{nT}$ for quiet times, respectively. The resulting thermospheric disturbances are very much the same as shown in Fig. 5. Since AE is derived solely from Northern Hemisphere measurements we prefer to use $\mathrm{Kp}$ for grouping our data. The use of these two datasets facilitates a comparison with earlier thermospheric studies that sorted the data by the same activity index.

We present the average mass density distribution around midnight (bin 2) in Figs. 3 and 4 for the events during active and quiet periods, respectively. The shapes of the curves at the two activity levels are quite similar, but the mean level is enhanced by approximately $40 \%$ at low latitudes and by $20 \%$ at high latitudes during active times. We relate this change in background mass density to the influence of direct driving by the solar wind. Müller et al. (2009) quantified the increase of mass density at low latitudes. According to their Fig. 11 the density enhancement by magnetic activity is given by

$\rho=\rho_{\text {quiet }}+0.012 \Delta a_{\mathrm{p}}$

where $\rho_{\text {quiet }}$ is the average density in $\left[10^{-12} \mathrm{~kg} / \mathrm{m}^{3}\right]$ during quiet periods. For our samples we obtain average magnetic activity indices of $a_{\mathrm{p}}=5$ and $a_{\mathrm{p}}=65$ for quiet and active events, respectively. From that difference we expect an enhancement of the low latitude density of $0.7 \times 10^{-12} \mathrm{~kg} / \mathrm{m}^{3}$. The actually observed difference between the black curves in Figs. 3 and 4 (before substorm arcs) amounts to $0.6 \times$ $10^{-12} \mathrm{~kg} / \mathrm{m}^{3}$, which explains the influence of magnetic activity reasonably well.

At high latitudes the differences between the black curves is smaller. In this region two processes are known to be driven by Joule heating: (1) thermal expansion of the atmosphere and (2) composition change. Vertical winds move up heavier molecules $\left(\mathrm{N}_{2}\right.$ and $\left.\mathrm{O}_{2}\right)$ across pressure levels. At a given altitude well above the heating region, the first effect always causes a mass density enhancement, while the second one may cause a density reduction due to a smaller scale height of the heavier particles. Both increases and decreases have been observed over active regions (Prölss, 1982; Prölss et al., 1988; Lei et al., 2010). This competition of effects may also explain the lack of density enhancement reflected by the green curve in the upper right frame of Fig. 5 at high latitudes.

Details of the substorm-related mass density disturbances are presented in Fig. 5. For the three different local time sectors we see clearly the temporal/spatial evolution of the density anomaly. The density bulges generated at auroral latitudes propagate equatorward at an average speed of $650 \mathrm{~m} / \mathrm{s}$ as travelling atmospheric disturbances (TADs). TADs occurring during times of magnetic activity have been reported early (e.g. Prölss, 1982, 1993; Prölss and Očko, 2000, and 
references therein). More recently, Bruinsma and Forbes (2007) investigated the dynamics of TADs occurring in connection with the magnetic storm on 29 May 2003. However, in our study, we present TADs as a direct response to a substorm onset as seen by a LEO satellite. In the time sector around midnight we observe the clearest signal. The density peaks occur first at $74^{\circ}$ Mlat, approximately $10^{\circ}$ poleward of the average onset latitude, and in longitude about an hour later in local time than the break-up. This implies that the main part of the energy may be dumped after the poleward leap of the aurora in the sector around midnight. In the sector past midnight (bin 3) substorms seem to have little effect on the density. The dominantly downward directed FACs in that region are obviously less efficient in heating.

For visualizing the dynamics of the thermospheric disturbance in an Earth-fixed frame we consider all six frames in Fig. 5 simultaneously.

This allows us to separate to a certain degree the temporal and spatial effects on the thermospheric mass density. Figure 11 illustrates schematically the measurement setup as seen from the ground. Successive CHAMP passes are separated by $23^{\circ}$ in longitude and proceed westwards. The abscissa in Fig. 11 represents relative longitudes, i.e. for a given event a certain constant value has to be added. Measurements from the three local time sectors (bins) are marked by different line styles. (bin 1: full line, bin 2: dotted line, bin 3: crossed line). Again, the colours of the lines indicate the sampling time after the substorm onset.

The results of the three local time bins may be interpreted as simultaneous measurements from three spacecraft flying side-by-side, separated by $23^{\circ}$ in longitude. The pink shaded band marks the path of an equatorward TAD wave front when the propagation speed and the Coriolis force are taken into account. The TAD path was determined using

$\lambda(n)=\lambda_{0}(n)-\left[\sum_{i=1}^{n}\left(v_{E_{\mathrm{rot}}} \cos \left(\theta_{0}-i\right)-v_{0}\right) \frac{1}{v_{\mathrm{TAD}}}\right] \frac{1}{\cos \left(\theta_{0}-n\right)}$

where $(\lambda, \theta)$ denote longitudes and latitudes, respectively, and $\left(\lambda_{0}, \theta_{0}\right)$ are the starting values. The starting latitude for the wave front is chosen at $\theta_{0}=74^{\circ}$, where density peaks occur first (see Fig. 5). $n$ is the distance the TAD has travelled equatorward in discrete steps of $1^{\circ}$ latitude. $v_{E_{\text {rot }}}$ denotes the rotation speed of the Earth at the equator, $490 \mathrm{~m} / \mathrm{s}$. $v_{0}$ is the rotation speed at $\theta_{0}=74^{\circ}, v_{E_{\text {rot }}} \cos \left(\theta_{0}\right)=135 \mathrm{~m} / \mathrm{s}$, while $v_{\mathrm{TAD}}$ is set $650 \mathrm{~m} / \mathrm{s}$. Horizontal, coloured lines mark the position of the TAD at the times of the first, second and third CHAMP pass after substorm onset.

By comparing the observations in Fig. 5 with our straightforward predictions illustrated in Fig. 11 we may get a better insight into the dynamics of the thermospheric disturbance. For an observer on the ground the TAD is propagating equatorward and westward. The latter motion is caused by the Coriolis force. For verifying this motion we check Fig. 5. The initial longitude of the substorm onset (red horizontal line in Fig. 11) was deliberately chosen to cover LT bins 1 and 2. At the time of the second pass after $T_{0}$ (blue lines) the TAD can be found in Fig. 5 at mid latitudes in bins 1 and 2 . There is almost no effect in bin 3. When turning to Fig. 11 the TAD wave front (blue horizontal line) is crossed by the blue dotted and solid lines that correspond to bins 2 and 1 observations, respectively. The blue crossed line is east of the disturbance zone, in accordance with the observations in bin 3. At the time of the third satellite pass (green curves) the TAD has reached the equator.

The largest effect is observed in bin2 and a smaller one in bin1 (cf. Fig. 5). Bin 3 is practically left unperturbed. This observation is not consistent with the prediction in Fig. 11. The westward shift of consecutive CHAMP orbits should have overtaken the westward propagation of the TAD. As a consequence, the crossed green line (bin 3) crosses now the TAD front at the equator, but the solid green line (bin 1) does not (cf. Fig. 11). This apparent discrepancy with the observations can be reconciled if we assume a faster westward drift of the TAD than the one caused by the Coriolis force. At this stage we have no conclusive explanation to offer. A possible suggestion is that the heating region expands westward with increasing time after onset in accordance with the westward travelling surge. This will cause the TAD front to be tilted slightly from north-west to south-east. Such a disturbance front should have an additional propagation component in westward direction. Supporting evidence is provided by Shibata and Schlegel (1993) who report a wave propagation oriented normally about $200^{\circ}$ in azimuth (i.e. $20^{\circ}$ west of southward direction) for atmospheric gravity waves excited at auroral latitudes.

When comparing the observed features with the TAD characteristics outlined in Sect. 1, we find agreement in all three points: propagation velocity, westward drift and little amplitude attenuation towards low latitudes on the nightside.

Some of the curves in Fig. 5 show unexpected variations. For example the red one in the top left frame exhibits an equatorial maximum right after the substorm. We interpret this as a remnant of a substorm that occurred about $3 \mathrm{~h}$ before the considered event. Ritter and Lühr (2008) showed a recurrence tendency of substorms every three hours during active periods. During quiet periods events are more isolated. In order to test this assumption we re-ran the superposed epoch analysis for the bin 1 dataset with isolated events only, i.e. no substorms occurred during a period of $4 \mathrm{~h}$ prior to the substorm onset (for $\mathrm{Kp}>4$ ). For this reduced dataset the air density amplitude near the equator of the first passes after the substorm onset is close to zero (not shown).

We may classify the presented TADs as large scale wave phenomena with a mean phase velocity of $650 \mathrm{~m} / \mathrm{s}$. Our results can be compared with storm-induced large-scale travelling ionospheric disturbances (LSTID). Borries et al. (2009) reported recently about LSTID observations over Europe. Their waves are also excited in the auroral region and propagate equatorward at a similar speed $(680 \mathrm{~m} / \mathrm{s}$ on average). 


\subsection{Thermospheric wind disturbances}

In order to bring the substorm-related disturbance wind into the context of prevailing winds we first have a look at the latitude distribution of the average zonal wind around midnight for active and quiet magnetic conditions, as shown in Figs. 7 and 8, respectively. From the comparison of the activity states it becomes obvious that a westward directed disturbance wind results from the difference between the two graphs. The velocity of the delta wind increases from about $20 \mathrm{~m} / \mathrm{s}$ at the equator to $50 \mathrm{~m} / \mathrm{s}$ towards higher latitudes. At latitudes poleward of $58^{\circ}$ Mlat the difference oscillates about zero. This behaviour of the disturbance wind is consistent with predictions derived from the recent DWM07 empirical wind model (Emmert et al., 2008).

It should be noted here that the difference of the wind profiles before and after the substorm in Figs. 7 and 8 is much smaller than the delta zonal wind caused by enhanced background activity. This impression is confirmed when looking at the wind differences caused by substorms (cf. Fig. 9). At low and mid latitudes the clearest westward delta winds are detected in the local time sector west of the substorm onset. Variations in other local time sectors cannot be regarded significant when considering the uncertainty of $\pm 10 \%$ of the wind estimates. As mentioned in Sect. 2.2 CHAMP can only detect zonal winds.

At high latitudes beyond $60^{\circ}$ Mlat we observe systematic substorm-related differences between the local time sectors (bins). In bins 1 and 2 positive deflections are found while bin 3 exhibits negative deflections. In all bins the blue curves $(\approx 2 \mathrm{~h}$ after onset) show this effect best.

This signature implies that a substorm evokes a converging delta zonal wind at auroral latitudes with a focus shortly after midnight. Such a zonal wind pattern is consistent with the simulation results of Fujiwara and Miyoshi (2006). After a transient enhancement of the cross-polar cap potential to $60 \mathrm{kV}$, their general circulation model (GCM) predicts strong equatorward winds of the order of $300 \mathrm{~m} / \mathrm{s}$ around midnight. From their Fig. 2b we may deduce weak converging zonal winds as observed in our study. This wind pattern forms in connection with TADs.

Substorms occurring during magnetically quiet periods have no appreciable influence on thermospheric zonal winds.

\section{Summary}

We have investigated the disturbance of the thermosphere by geomagnetic substorms. Based on a large number of substorm events the average effects on mass density and zonal winds at CHAMP altitude were determined in a statistical study. Superposed epoch analysis was applied with satellite data to obtain the characteristic temporal and spatial variations based on a large number of these transient events. Separate analyses were performed for events under quiet $(\mathrm{Kp} \leq 2)$ and disturbed conditions $(\mathrm{Kp}>4)$. Substorms during quiet times have a negligible effect on the thermosphere. During magnetically active periods, however, a number of features due to substorms have been identified.

1. Mass density enhancements by about $15 \%$ occur first at auroral latitudes some $10^{\circ}$ in latitude poleward of the onset in the local time sector 22-01 MLT.

2. A density bulge propagates as TAD equatorward at a mean velocity of $650 \mathrm{~m} / \mathrm{s}$. About $3.5 \mathrm{~h}$ after onset the bulges from the Northern and Southern Hemispheres meet and pile up at the equator. The attained density enhancement is almost $20 \%$. This substorm-related effect probably contributes to a certain extent to the wellknown equatorial midnight density anomaly.

3. For an observer on ground the TAD front propagates equatorward and westward. The effect of the Coriolis force is not sufficiently large to support the observed westward displacement of the bulge at the equator. An additional westward velocity of the order of $150 \mathrm{~m} / \mathrm{s}$ is required to explain the satellite measurements.

4. Substorms do not have a large influence on thermospheric zonal winds. However, overall magnetic activity in the range of $\mathrm{Kp}=5$ adds a westward wind component of the order of $50 \mathrm{~m} / \mathrm{s}$ to the zonal wind at mid latitudes.

5. Substorm-related zonal winds at mid latitudes were only identified in the sector west of the substorm onset. Here, we find a westward disturbance wind of about $20 \mathrm{~m} / \mathrm{s}$.

6. At high latitudes (poleward of $60^{\circ}$ Mlat) eastward disturbance winds of the order of $20 \mathrm{~m} / \mathrm{s}$ are recorded in the pre-midnight and midnight sector in response to a substorm. These converging zonal winds are associated with the formation of TADs and they are accompanied by strong equatorward winds, as GCM simulations predict (Fujiwara and Miyoshi, 2006). In the post-midnight sector we observe westward disturbance winds of $50 \mathrm{~m} / \mathrm{s}$.

The results obtained here are regarded a suitable benchmark for testing ionospheric-thermospheric dynamics models during magnetically active periods.

Acknowledgement. We are obliged to H. Frey of SWRI, UC Berkeley, for making available the catalogue of auroral substorm onsets obtained from IMAGE-FUV observations. The CHAMP mission is sponsored by the Space Agency of the German Aerospace Center (DLR) through funds of the Federal Ministry of Economics and Technology, following a decision of the German Federal Parliament (grant code 50EE0944). The data retrieval and operation of the CHAMP satellite by the German Space Operations Center (GSOC) of DLR is acknowledged.

Topical Editor K. Kauristie thanks two anonymous referees for their help in evaluating this paper. 


\section{References}

Akasofu, S.-I.: The development of the auroral substorm, Planet. Space Sci., 12, 273-282, 1964.

Borries, C., Jakowski, N., and Wilken, V.: Storm induced large scale TIDs observed in GPS derived TEC, Ann. Geophys., 27, 16051612, 2009, http://www.ann-geophys.net/27/1605/2009/.

Bruinsma, S. L. and Forbes, J. M.: Global observation of traveling atmospheric disturbances (TADs) in the thermosphere, Geophys. Res. Lett., 34, L14103, doi:10.1029/2007GL030243, 2007.

Burns, A. G. and Killeen, T. L.: The equatorial neutral thermospheric response to geomagnetic forcing, Geophys. Res. Lett., 19, 977-981, 1992.

Caan, M. N., McPherron, R. L., and Russell, C. T.: Substorm and interplanetary magnetic field effects on the geomagnetic tail lobes, J. Geophys. Res., 80, 191-194, 1975.

Demars, H. G. and Schunk, R. W.: Thermospheric response to ion heating in the dayside cusp, J. Atmos. Solar-Terr. Phys., 69, 649660, 2007.

Doornbos, E., van den IJssel, J., Lühr, H., Förster, M., and Koppenwallner, G.: Neutral Density and Crosswind Determination from Arbitrarily Oriented Multiaxis Accelerometers on Satellites, J. Spacecr. Rock., in press, doi:10.2514/1.48114, 2010.

Drob, D. P., Emmert, J. T., Crowley, G., Picone, J. M., Shepherd, G. G., Skinner, W., Hays, P., Niciejewski, R. J., Larsen, M., She, C. Y., Meriwether, J. W., Hernandez, G., Jarvis, M., Sipler, D., Tepley, C. A., O’Brien, M. S., Bowman, J. R., Wu, Q., Murayama, Y., Kawamura, S., Reid, I. M., and Vincent, R. A.: An empirical model of the Earth's horizontal wind fields: HWM07, J. Geophys. Res., 113, A12304, doi:10.1029/2008JA013668, 2008.

Emmert, J. T., Fejer, B. G., Shepherd, G. G., and Solheim, B. H.: Altitude dependence of middle and low-latitude daytime thermospheric disturbance winds measured by WINDII, J. Geophys. Res., 107, D1483, doi:10.1029/2002JA009646, 2002.

Emmert, J. T., Drob, D. P., Shepherd, G. G., Hernandez, G., Jarvis, M. J., Meriwether, J. W., Niciejewski, R. J., Sipler, D. P., and Tepley, C. A.: DWM07 global empirical model of upper thermospheric storm-induced disturbance winds, J. Geophys. Res., 113, A11319, doi:10.1029/2008JA013541, 2008.

Förster, M., Rentz, S., Köhler, W., Liu, H., and Haaland, S. E.: IMF dependence of high-latitude thermospheric wind pattern derived from CHAMP cross-track measurements, Ann. Geophys., 26, 1581-1595, 2008, http://www.ann-geophys.net/26/1581/2008/.

Frey, H. U. and Mende, S. B.: Substorm onsets as observed by IMAGE-FUV, Int. Conf. Substorms, 8, 71-75, 2006.

Fujiwara, H. and Miyoshi, Y.: Characteristics of the largescale traveling atmospheric disturbances during geomagnetically quiet and disturbed periods simulated by a whole atmosphere general circulation model, Geophys. Res. Lett., 33, L20108, doi:10.1029/2006GL027103, 2006.

Fujiwara, H., Maeda, S., Fukunishi, H., Fuller-Rowell, T. J., and Evans, D. S.: Global variations of therrnospheric winds and temperatures caused by substorm energy injection, J. Geophys. Res., 101(A1), 225-239, 1996.

Hocke, K. and Schlegel, K.: A review of atmospheric gravity waves and traveling ionospheric disturbances: 1982-1995, Ann. Geophys., 12, 917-940, 1996.
Kikuchi, T., Lühr, H., Kitamura, T., Saka, O., and Schlegel, K.: Direct Penetration of the Polar Electric Field to the Equator During a DP2 Event as Detected by the Auroral and Equatorial Magnetometer Chains and the EISCAT Radar, J. Geophys. Res., 101, 17161-17173, 1996.

Kwak, Y.-S., Richmond, A. D., Deng, Y., Forbes, J. M., and Kim, K.-H.: Dependence of the high-latitude thermospheric densities on the interplanetary magnetic field, J. Geophys. Res., 114, A05304, doi:10.1029/2008JA013882, 2009.

Lei, J., Thayer, J. P., Burns, A. G., Lu, G., and Deng, Y.: Wind and temperature effects on thermosphere mass density response to the November 2004 geomagnetic storm, J. Geophys. Res., 115, A05303, doi:10.1029/2009JA014754, 2010.

Liu, H., Lühr, H., Henize, V., and Köhler, W.: Global distribution of the thermospheric total mass density derived from CHAMP, J. Geophys. Res., 110, A04301, doi:10.1029/2004JA010741, 2005.

Lühr, H., Rother, M., Köhler, W., Ritter, P., and Grunwaldt, L.: Thermospheric up-welling in the cusp region: Evidence from CHAMP observations, Geophys. Res. Lett., 31, L06805, doi:10.1029/2003GL019314, 2004.

Lühr, H., Rentz, S., Ritter, P., Liu, H., and Häusler, K.: Average thermospheric wind patterns over the polar regions, as observed by CHAMP, Ann. Geophys., 25, 1093-1101, 2007, http://www.ann-geophys.net/25/1093/2007/.

Müller, S., Lühr, H., and Rentz, S.: Solar and magnetospheric forcing of the low latitude thermospheric mass density as observed by CHAMP, Ann. Geophys., 27, 2087-2099, 2009, http://www.ann-geophys.net/27/2087/2009/.

Picone, J. M., Hedin, A. E., Drob, D. P., and Aikin, A. C.: NRLMSISE-00 empirical model of the atmosphere: Statistical comparisons and scientific issues, J. Geophys. Res., 107(A12), 1468, doi:10.1029/2002JA009430, 2002.

Prölss, G. W.: Perturbation of the low-latitude upper atmosphere during magnetic substorm activity, J. Geophys. Res., 87, 52605266, 1982.

Prölss, G. W.: Common Origin of Positive Ionospheric Storms at Middle Latitudes and the Geomagnetic Activity Effect at Low Latitudes, J. Geophys. Res., 98(A4), 5981-5991, 1993.

Prölss, G. W. and Očko, M.: Thermospheric Response to a Magnetic Substorm, Adv. Space Res., 26(1), 131-135, 2000.

Prölss, G. W., Roemer, M., and Slowey, J.: Dissipation of solar wind energy in the earth's upper atmosphere: The geomagnetic activity effect, Adv. Space Res., 8 (5), 215-261, 1988.

Reigber, C., Lühr, H., and Schwintzer, P.: CHAMP mission status, Adv. Space Res., 30(2), 129-134, 2002.

Rentz, S. and Lühr, H.: Climatology of the cusp-related thermospheric mass density anomaly, as derived from CHAMP observations, Ann. Geophys., 26, 2807-2823, 2008, http://www.ann-geophys.net/26/2807/2008/.

Richmond, A. D.: Ionospheric electrodynamics using magnetic apex coordinates, J. Geomag. Geoelectr., 47, 191-212, 1995.

Richmond, A. D. and Matsushita, S.: Propagation of upper atmospheric storm effects towards lower latitudes, J. Geophys. Res, 80, 2839-2850, 1975.

Ritter, P. and Lühr, H.: Near-Earth magnetic signature of magnetospheric substorms and an improved substorm current model, Ann. Geophys., 26, 2781-2793, 2008, http://www.ann-geophys.net/26/2781/2008/.

Schlegel, K., Lühr, H., St.-Maurice, J.-P., Crowley, G., and Hack- 
ert, C.: Thermospheric density structures over the polar regions observed with CHAMP, Ann. Geophys., 23, 1659-1672, 2005, http://www.ann-geophys.net/23/1659/2005/.

Shibata, T. and Schlegel, K.: Vertical structure of AGW-associated ionospheric fluctuations in the E- and lower F-region observed with EISCAT - a case study, J. Atmos. Terr. Phys., 55, 739-749, 1993.

VanHelleputte, T., Doornbos, E., and Visser, P.: CHAMP and GRACE accelerometer calibration by GPS-based orbit determination, Adv. Space Res., 43(12), 1890-1896, 2009.
Wang, H., Lühr, H., Ma, S. Y., and Ritter, P.: Statistical study of the substorm onset: its dependence on solar wind parameters and solar illumination, Ann. Geophys., 23, 2069-2079, 2005, http://www.ann-geophys.net/23/2069/2005/.

Wang, H., Lühr, H., Ma, S. Y., and Frey, H. U.: Interhemispheric comparison of average substorm onset locations: evidence for deviation from conjugacy, Ann. Geophys., 25, 989-999, 2007, http://www.ann-geophys.net/25/989/2007/. 